\title{
Metaheuristic Approach of Multi-Objective Optimization during EDM Process
}

\author{
Goutam Kumar Bose*, Pritam Pain ${ }^{\#}$ \\ Department of Mechanical Engineering \\ Haldia Institute of Technology, Haldia, West Bengal, India

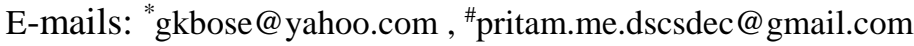 \\ ${ }^{*}$ Corresponding author
}

(Received October 13, 2017; Accepted December 2, 2017)

\begin{abstract}
In modern-day manufacturing Electric Discharge Machining (EDM) process has successfully placed itself in the domain of precision machining and generating complex geometries where secondary machining processes are eliminated. In this research paper, a die sinking EDM is applied to machine mild steel in order to measure the different multi-objective results like Material Removal Rate (MRR) and Over Cut (OC). This contradictory objective is accomplished by using the control parameters like a pulse on time, duty factor, gap current and spark gap employing copper tool with lateral flushing. Here the individual objective function of the responses is created through regression analysis. Primarily the contradictory objectives are optimized by employing Taguchi Methodology, then Regression analysis is done on the test results. Additionally, the experimental results are optimized using Response Surface Methodology (RSM). It is followed by a multi-objective optimization through Overlaid contour plots and Desirability functions to ascertain the best parametric combination amongst the set of feasible alternatives.
\end{abstract}

Keywords- Mild Steel, Regression, Response surface methodology, Overlaid control plot, Desirability function, MRR, Overcut.

\section{Introduction}

As the modern day looks for advance and superior material to survive in the adverse working environment, they call for hard and high-temperature resistive material; which are very difficult to machine by the traditional machining process. To sustain this challenging situation non-traditional machining is essential. Electrical Discharge Machining (EDM) is a non-conventional machining process that can remove the conductive material by control erosion. In this process, the cathode tool and the anode work piece are separated by a small spark gap and both the tool and the work piece are submerged in the dielectric fluid. When the current passes through, then a high number of electrons from the tool starts to flow towards the work piece like a plasma channel, and as a result, the work piece instantaneously melts and vaporize. The removed material is then flashed always by the continuously flowing dielectric fluid. As the tool and the work piece does not come in direct contact during machining, so the hardness of the work piece is not a factor in this machining process. This process can develop work piece having a complicated shape and profile. The major factors which can influence this process are like work piece material, pulse on time, flushing pressure of the dielectric fluid, duty factor, spark gap, the voltage applied, gap current, retract distance etc. (Kiyak and Cakir, 2007). Finest machining parameters are attained by a thorough analysis of all the control parameters which have the significant effect on the process. In this research work Design of Experiment (DOE) is used, which is a very promising method to find out the optimal machining condition in various manufacturing processes (Varun et al., 2012). The following Fig. 1 illustrated the setup of the EDM process. 


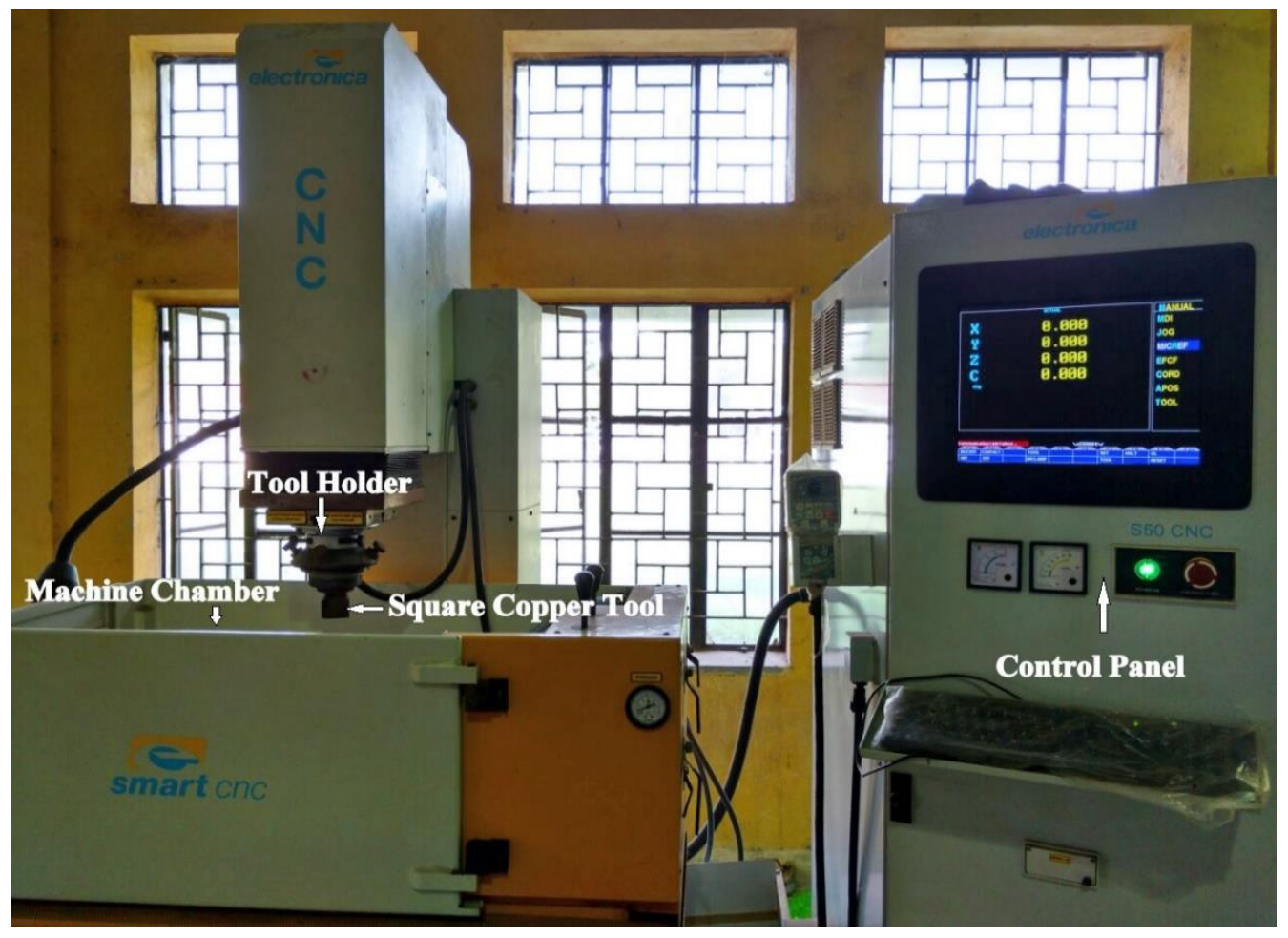

Fig. 1. Illustration of EDM setup

A brief detail of the past research work on EDM is presented here. Meena and Nagahanumaiah (2006) as optimized the EDM process parameters while machining EN24 steel using direct metal laser sintering electrodes and find out that the current is the most affecting parameter for machining and porosity is the main cause of electrode wear. Nadpara and Choudhary (2014) Find out that the important parameter to increase the Material Removal Rate (MRR) during machining of D3 steel is peak current and they also concluded that this peak current has also the most effect on the tool wear. Aliakbari and Baseri (2012) has studied the rotary EDM process and optimized the machining parameter taking the rotary speed as one of the machining control parameters. Nipanikar (2012) has optimized the EDM parameters for machining of D3 Steel and also find out the tool wear during machining. Vinoth and Pradeep (2014) has investigated on the cryogenic cooling of liquified $\mathrm{Cu}$ (copper) tool used in EDM process and optimized various process parameters. Sharma et al. (2014) have used hybrid EDM process to increase the MRR as well as to reduce the tool wear rate and taper angle at the same time by using a copper tool and brass tool and they find out that the copper tool gives a more optimized result. Vishwakarma et al. (2012) have employed regression equation to find out the most significant process parameter during machining of EN 19 Steel in EDM process. Krishna and Xavior (2015) have employed response surface methodology optimization process on machining of industrial grade material and find out optimal machining configuration for end milling process. Pandey et al. (2014) have optimized different process parameters individually for the micro-EDM process by genetic algorithm and then used response surface methodology to find out the interrelationship in between input parameters and responses. Lin et al. (2012) used the micro-EDM process to machining SK3 carbon tool steel and find out that peak current is the most affecting parameter for this machining process. 
International Journal of Mathematical, Engineering and Management Sciences

Vol. 3, No. 3, 301-314, 2018

https://dx.doi.org/10.33889/IJMEMS.2018.3.3-022

It is found out from the past research study that there is no substantial work has done on EDM process by considering four parameters such as Pulse on Time, Duty Factor, Gap current, and Spark Gap to evaluate the effect on different responses which are contradictory in nature like material removal rate and overcut. This research work aimed to achieve an optimal solution to obtain two contradictory objectives simultaneously while machining by using a cylindrical shaped copper $(\mathrm{Cu})$ tool. Response surface methodology is employed to obtain high MRR and low Over Cut (OC). The control plots demonstrate the feasible region to obtain those objectives simultaneously within the range of control parameters.

\section{Experimental Setup}

In this machining process "ELECTRONICA-S50 CNC" type EDM is used. This die-sinking servohead machine maintains a constant gap between the tool and the work-piece. Paraffin oil (specific gravity of 0.850 at $25^{\circ} \mathrm{C}$ ) is used as dielectric fluid with lateral flushing of pressure $0.2 \mathrm{kgf} / \mathrm{cm}^{2}$. $\mathrm{Cu}$ tool of a length of $16.2 \mathrm{~mm}$ with a diameter of $26.1 \mathrm{~mm}$ is used to remove the work-piece material which is made of Mild Steel with a dimension of $12 \times 12 \times 12 \mathrm{~mm}^{3}$. A servo control unit is installed in the machine to maintain the pre-defined gap between the tool and the work-piece. It maintains the gap by measuring the gap voltage and current and then regulates the gap distance. This machining setup also consists of X-Y axis moveable working table, working tank with job holding device, a tool holder, a feed pump etc.

The process control parameters are altered within the maximum and minimum range as presented in Table 1. The volumetric material removal rate is expressed as the ratio total volume removed from the work-piece to the machining time. So, the unit of MRR is $\mathrm{mg} / \mathrm{sec}$. The overcut is expressed as the difference between the tool diameter and the diameter of the cavity formed in the work-piece. In this purpose Toolmaker's microscope is used. The unit of the OC is expressed as $\mathrm{mm}^{2}$.

Table 1. Control parameters and levels

\begin{tabular}{|l|l|l|c|c|}
\hline \multirow{2}{*}{ Cutting Parameters } & \multirow{2}{*}{ Symbol } & \multirow{2}{*}{ Units } & \multicolumn{2}{|c|}{ Levels } \\
\cline { 4 - 5 } & & & Upper & Lower \\
\hline Pulse on time & POT & $(\mu \mathrm{S})$ & 3000 & 1500 \\
\hline Duty Factor & DF & & 32 & 20 \\
\hline Gap current & GI & $(\mathrm{Amp})$ & 30 & 20 \\
\hline Spark gap & SG & $(\mathrm{mm})$ & 0.36 & 0.20 \\
\hline
\end{tabular}

While experimenting, the control parameters are varied all together to save the time and the cost of experimentation. It also helps to find out the interaction in between the different parameters. Depending on the previous research work the main four control parameters chosen are Pulse On Time (POT), Duty Factor (DF), Gap current (GI) and Spark Gap (SG). The parameters are varied in three different level. However other parameters like tool material and the work piece, flushing pressure kept constant during the experiment. 
International Journal of Mathematical, Engineering and Management Sciences

Vol. 3, No. 3, 301-314, 2018

https://dx.doi.org/10.33889/IJMEMS.2018.3.3-022

\section{Regression Analysis}

The regression model contains a subset of two available conflicting regression, like (Montogomery, 2003):

- A regression model needs to contain as many as a possible regressor to make the final resultant equation to evaluate the outcomes.

- A regression model needs to contain as few as a possible regressor to reduce the cost of the model.

In this present experimentation, backward elimination method is applied having $\mathrm{L}_{9}$ Orthogonal Array (OA). Three graphs generated from the regression calculation, namely histogram of residual, normal probability plot and residual versus fits plot.

Histogram of residuals is an exploratory tool to explain general features of the data which incorporates typical values, dispersion, shape and also abnormal values in the data. Normal Probability Plot can predict the fit of a distribution for a given set of data. It also estimates percentiles, and compare different sample distributions. Residuals versus fits graph show an arbitrary distribution of residuals on either side of zero " 0 ". Fitted line plots graphically represent the fitted values for all $\mathrm{x}$-values in the region of significance. These plots are a convenient way to compare fitted values to actual data values in order to assess model fit.

\subsection{Analysis of the Material Removal Rate (MRR)}

The experimental model for Material Removal Rate from $\mathrm{L}_{9} \mathrm{OA}$ is shown in equation 1 below:

The estimated regression model equation for Material Removal Rate is:

$$
\begin{aligned}
& \mathrm{MRR}(\mathrm{gm} / \mathrm{sec})= \\
& 0.0046+0.000008 \mathrm{POT}-0.000142 \mathrm{DF}-0.000875 \mathrm{I}+0.00466 \mathrm{SG}-0.000000 \mathrm{POT} * \\
& \mathrm{DF}+0.000000 \mathrm{POT} * \mathrm{I}+0.000036 \mathrm{DF} * \mathrm{I}
\end{aligned}
$$

The result analysis from the experimental model is illustrated in the following Table 2. As the statistical T-value of POT is larger than the other three process control parameter like DF, I and SG, so POT is the most significant parameter for MRR. Also, the value of R-square is $93.42 \%$, it signifies that the data are very close to the mean.

Table 2. Estimated regression coefficient for MRR

\begin{tabular}{|l|c|c|c|c|c|}
\hline Term & Coef & SE Coef & T-Value & P-Value & VIF \\
\hline Constant & 0.0046 & 0.0261 & 0.18 & 0.888 & \\
\hline POT & 0.000008 & 0.000006 & 1.44 & 0.386 & 71.73 \\
\hline DF & -0.000142 & 0.000834 & -0.17 & 0.893 & 100.34 \\
\hline I & -0.000875 & 0.000910 & -0.96 & 0.512 & 82.81 \\
\hline SG & 0.00466 & 0.00668 & 0.70 & 0.613 & 1.07 \\
\hline POT*DF & -0.000000 & 0.000000 & -2.07 & 0.287 & 64.19 \\
\hline POT*I & 0.000000 & 0.000000 & 0.14 & 0.912 & 79.10 \\
\hline DF*I & 0.000036 & 0.000025 & 1.42 & 0.391 & 102.76 \\
\hline S=0.0012241; R-sq=93.42\%; R-sq(adj)=47.35\%; R-sq(pred) $=0 \%$ \\
\hline
\end{tabular}


International Journal of Mathematical, Engineering and Management Sciences

Vol. 3, No. 3, 301-314, 2018

https://dx.doi.org/10.33889/IJMEMS.2018.3.3-022

Fig. 2, Fig. 3 and Fig. 4 represent the histogram of residual, normal probably plot and residual versus fits plot for MRR respectively. From Fig. 2 Histogram for MRR shows a truncated distribution from right to left. From Fig. 3 the normal probability plot illustrates all the sample test are distributed near to the mean line. All the points in this plot look a straight line for all the output responses, as the residuals are normally distributed. As in the Residuals versus fits plot of MRR i.e. Fig. 4 has a recognizable pattern, so these examples have room for enhancement.

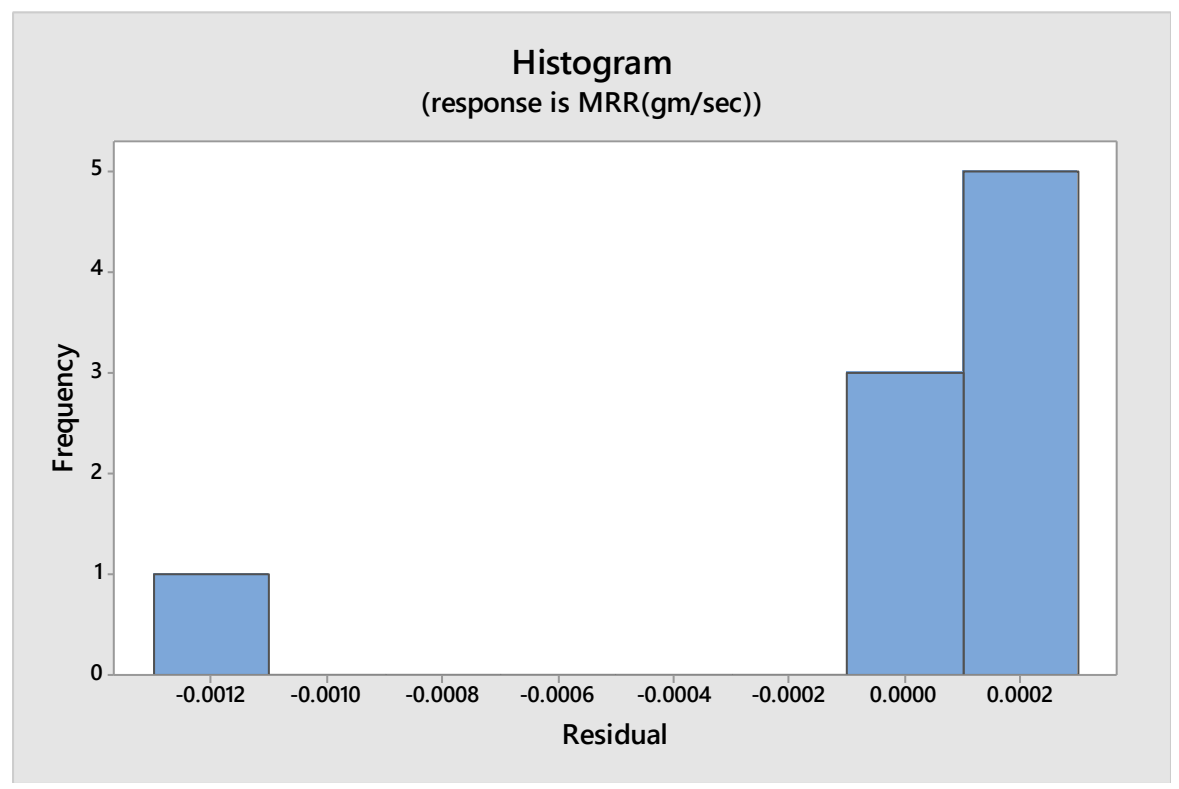

Fig. 2. Histogram for MRR

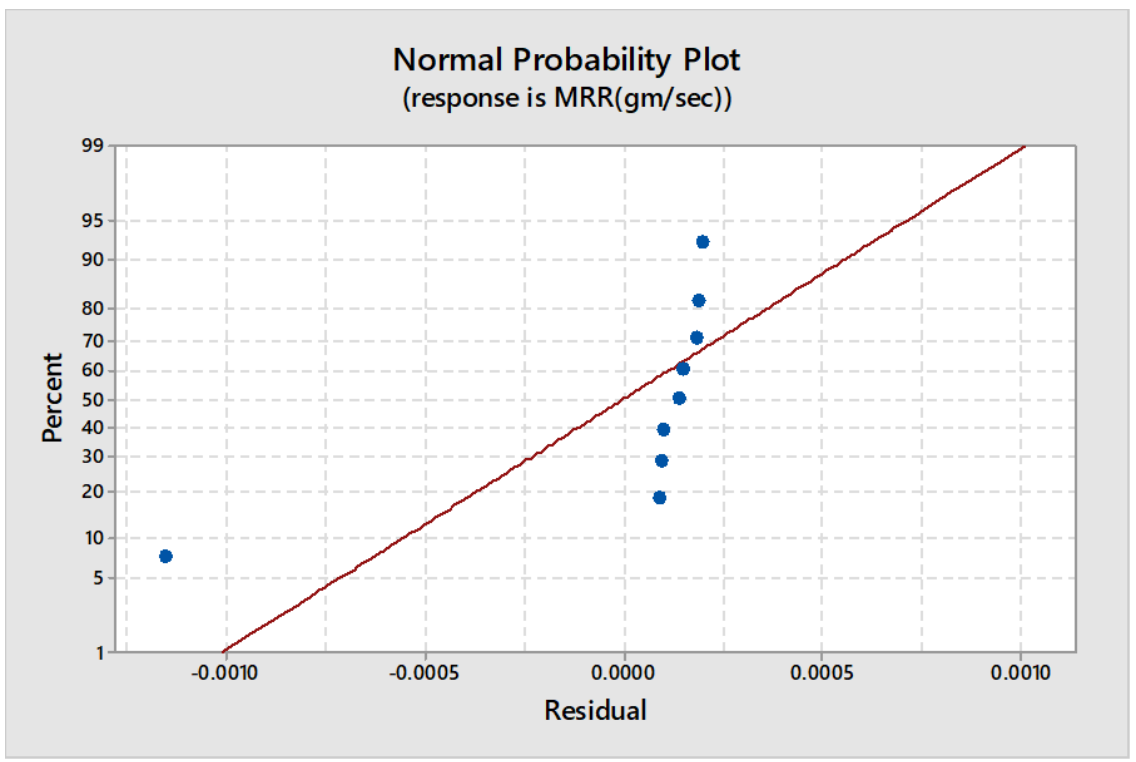

Fig. 3. Normal probability plot for MRR 
International Journal of Mathematical, Engineering and Management Sciences

Vol. 3, No. 3, 301-314, 2018

https://dx.doi.org/10.33889/IJMEMS.2018.3.3-022

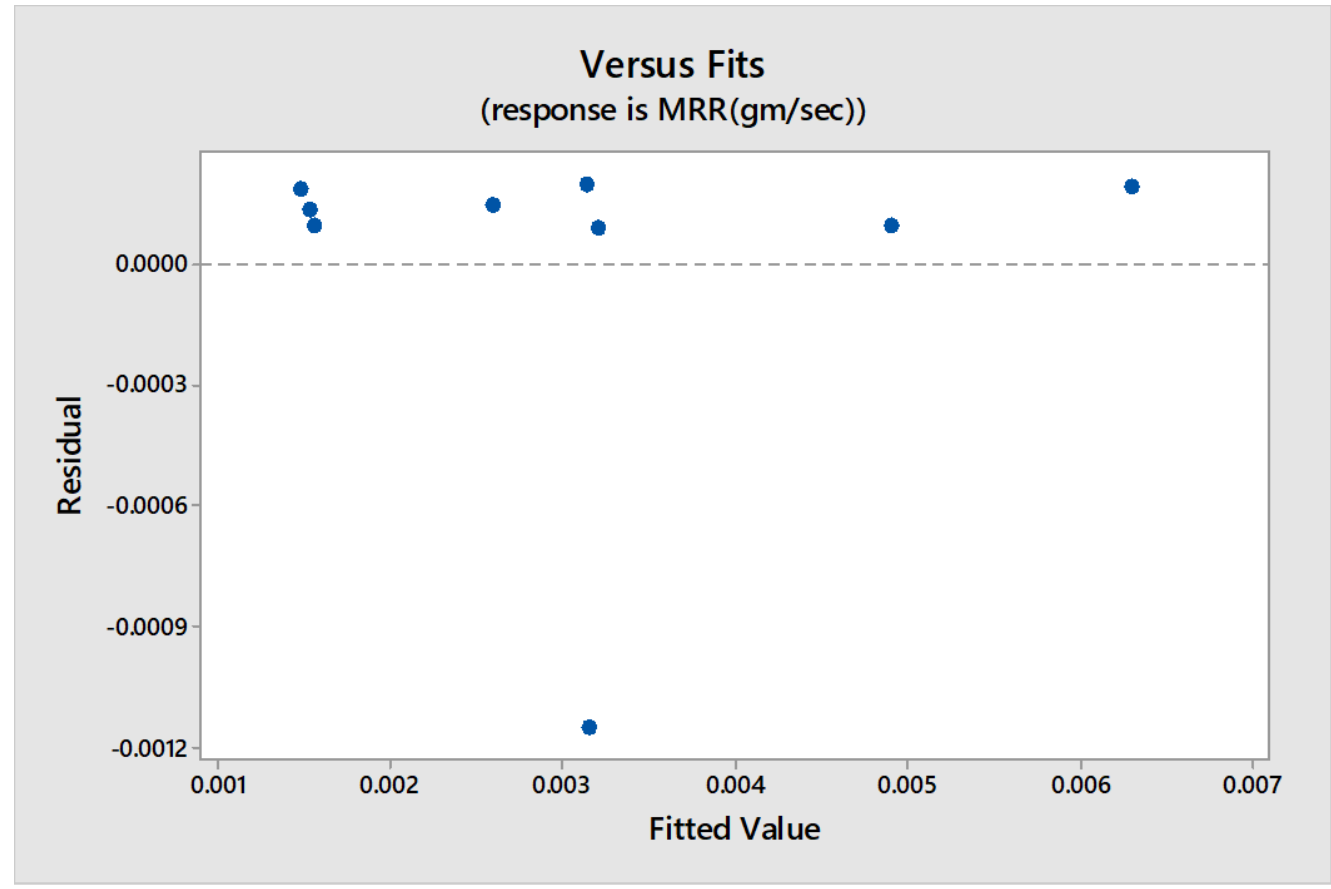

Fig. 4. Residuals versus fits plot for material removal rate

\subsection{Analysis of the Over Cut (OC)}

The empirical relation for $\mathrm{OC}$ from $\mathrm{L}_{9} \mathrm{OA}$ is shown in equation 2 below:

The estimated regression model equation for overcut is:

$\mathrm{OC}\left(\mathrm{mm}^{2}\right)=-622+0.102 \mathrm{POT}+18.1 \mathrm{DF}+25.6 \mathrm{I}-71 \mathrm{SG}-0.00005 \mathrm{POT} *$

$\mathrm{DF}-0.00465 \mathrm{POT} * \mathrm{I}-0.591 \mathrm{DF} * \mathrm{I}$

The result analysis from the experimental model is illustrated in the following Table 3 . As the statistical T-value of I is larger than the other three process control parameter like POT, DF, and SG, so I is the most significant parameter for OC. Also, the value of R-square is $73.97 \%$, it signifies that the data are not very close to the mean. So, it got a room to develop.

Table 3. Estimated regression coefficient for OC

\begin{tabular}{|l|c|c|c|c|c|}
\hline \multicolumn{1}{|c|}{ Term } & Coef & SE Coef & T-Value & P-Value & VIF \\
\hline Constant & -622 & 827 & -0.75 & 0.589 & \\
\hline POT & 0.102 & 0.176 & 0.58 & 0.666 & 71.73 \\
\hline DF & 18.1 & 26.4 & 0.68 & 0.618 & 100.34 \\
\hline I & 25.6 & 28.8 & 0.89 & 0.538 & 82.81 \\
\hline SG & -71 & 212 & -0.33 & 0.795 & 1.07 \\
\hline POT*DF & -0.00005 & 0.00528 & -0.01 & 0.994 & 64.19 \\
\hline POT*I & -0.00465 & 0.00635 & -0.73 & 0.598 & 79.10 \\
\hline DF*I & -0.591 & 0.803 & -0.74 & 0.596 & 102.76 \\
\hline S = 38.7860; R-sq = 73.97\%, R-sq (adj) $=0.00 \%$, R-sq (pred) $=0.00 \%$ \\
\hline
\end{tabular}


International Journal of Mathematical, Engineering and Management Sciences

Vol. 3, No. 3, 301-314, 2018

https://dx.doi.org/10.33889/IJMEMS.2018.3.3-022

Fig. 5, Fig. 6 and Fig. 7 displays the histogram of residual, normal probably plot and residual versus fits plot for OC respectively. From Fig. 5 Histogram of OC shows a skewed distribution from left to right. From Fig. 6 the normal probability plot illustrates each value with respect to the proportion of the sample values which are quite near to the mean value that means it fitted along the distribution line. As all the residuals are typically spread in this plot, as a result it forms a straight line for all the responses. In Fig. 7 Residuals versus fits plot of OC has a recognizable pattern, so these models have room for improvement.

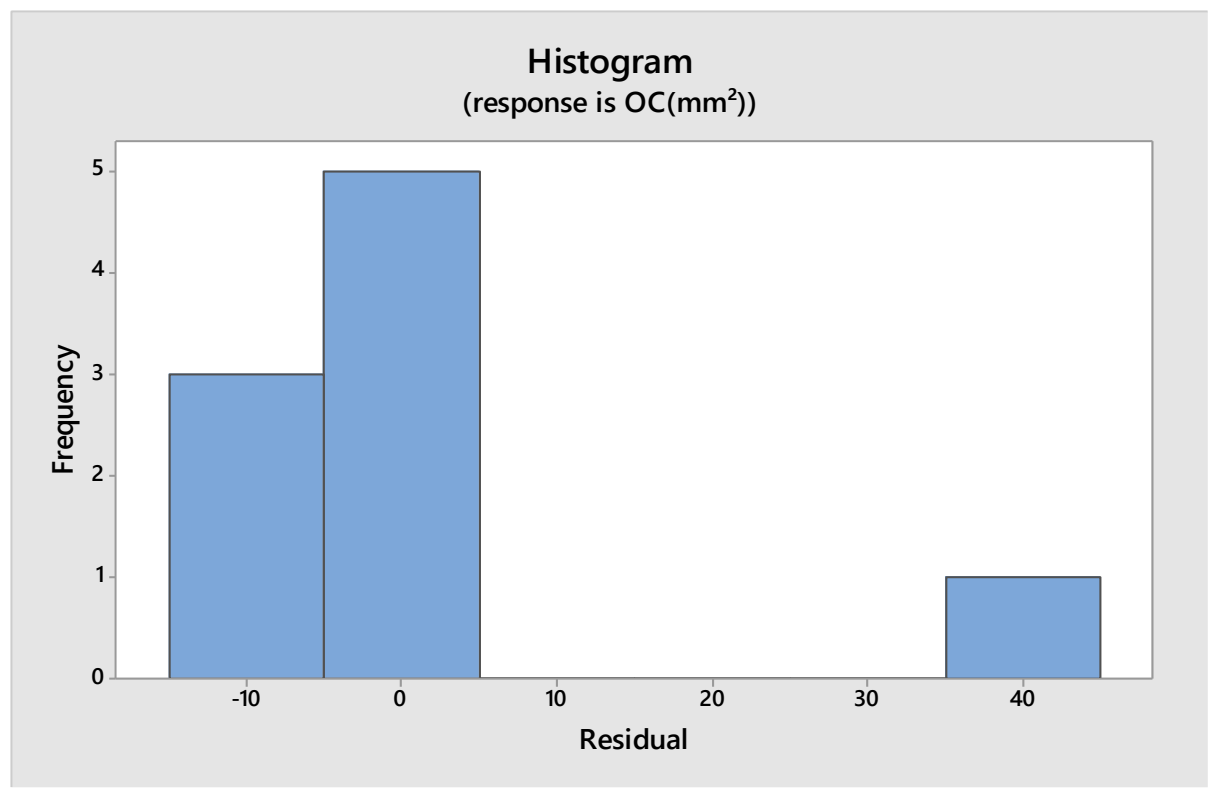

Fig. 5. Histogram for OC

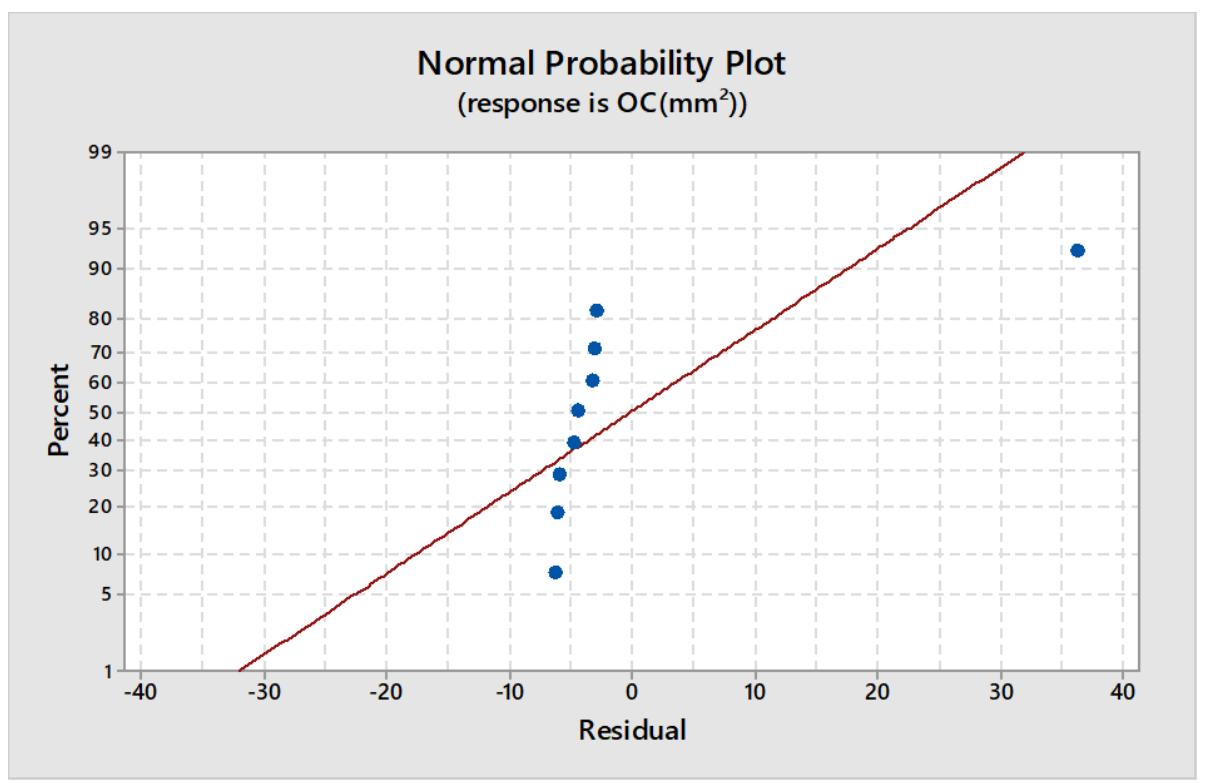

Fig. 6. Normal probability plot for OC 
International Journal of Mathematical, Engineering and Management Sciences

Vol. 3, No. 3, 301-314, 2018

https://dx.doi.org/10.33889/IJMEMS.2018.3.3-022

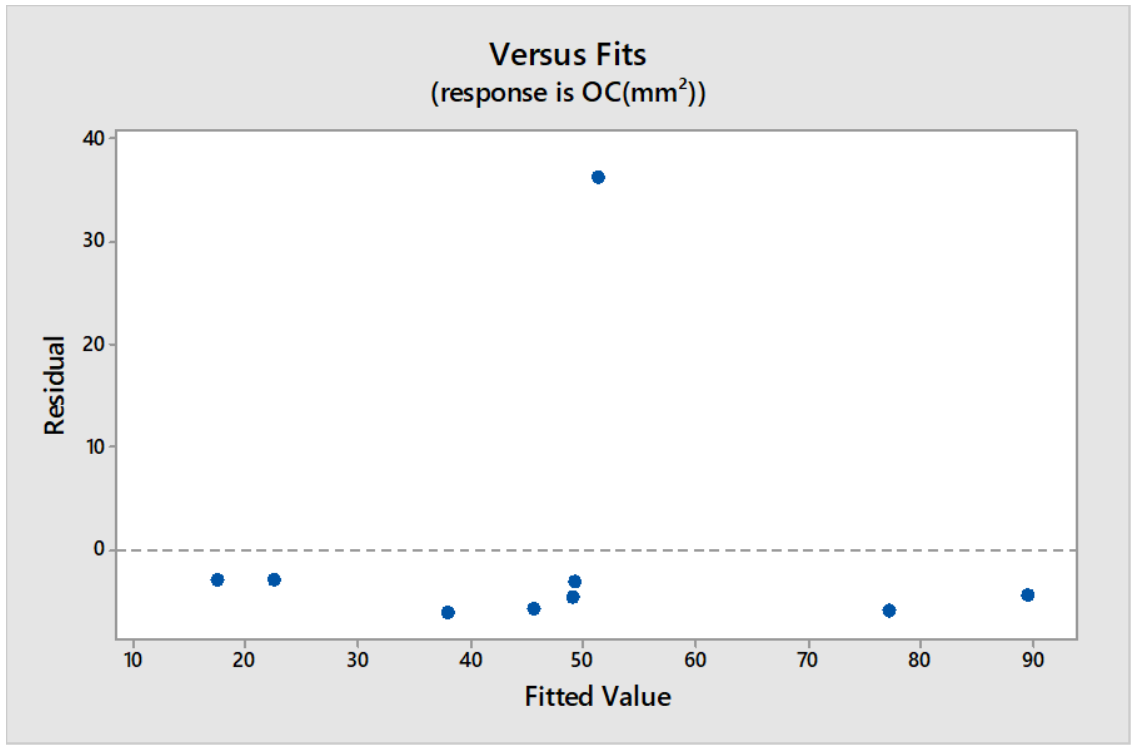

Fig. 7. Residuals versus fits plot for OC

\section{Response Surface Methodology (RSM)}

Response Surface Methodology (RSM) relates the relation between several process control variables and one or more responses. The RSM is used to obtain responses from a sequence of the designed experimental run. The individual variables are controlled by the experimenter, in a designed research, while the process response is a collected output during experimentation. Fig. 8 illustrates the inscribed type response surface design which has 5 level of factors and over all accuracy is good.

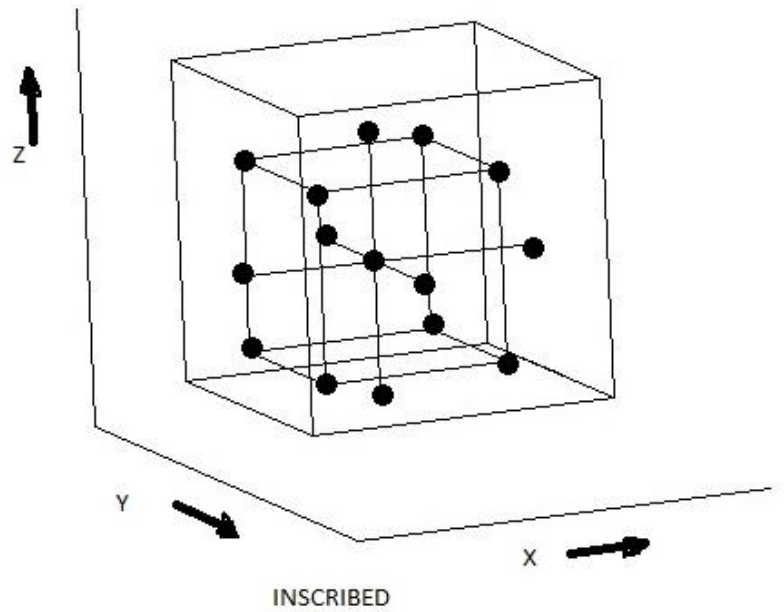

Fig. 8. Inscribed type response surface design 
International Journal of Mathematical, Engineering and Management Sciences

Vol. 3, No. 3, 301-314, 2018

https://dx.doi.org/10.33889/IJMEMS.2018.3.3-022

The response surface can be correlated with controllable variables like $\mathrm{X}_{1}, \mathrm{X}_{2} \ldots \ldots \mathrm{X}_{\mathrm{k}}$

As a function $y=f\left(X_{1}, X_{2} \ldots \ldots X_{k}\right)+\varepsilon$

The second order mathematical equation is established in order to formulate an input-output connection proficiently which takes the general form:

$y=\beta_{0}+\sum_{i=1}^{k} \beta_{i} x_{i}+\sum_{i=1}^{k} \beta_{i i} x_{i}^{2}+\sum_{i=1}^{k} \beta_{i j} x_{i} x_{j}+\varepsilon$

The calculated response for the model is

$\hat{y}=\hat{\beta}_{0}+\sum_{i=1}^{k} \hat{\beta}_{i} x_{i}+\sum_{i=1}^{k} \hat{\beta}_{i i} x_{i}{ }^{2}+\sum_{i=1}^{k} \hat{\beta}_{i j} x_{i} x_{j}$

In the present research work, Box-Behenken Design is used which is based on $2^{\mathrm{k}}(\mathrm{k}=4)$ factorials with incomplete designs and found to be very efficient. The process variables combinations and the corresponding responses are presented in Table 4.

\subsection{Analysis of the Test Result for Material Removal Rate}

The response surface (RSM) graph of MRR regarding POT, DF, SG and I are exposed in Fig. 9. In these plots, MRR is taken in the z-axis and at the time two control parameters are varied in $\mathrm{x}$-axis and y-axis respectively, while other two parameters are kept constant. It is evident from the graph that the highest points of the control parameters produce an extreme response. Since the response is fully dependent on the variables therefore they cannot have any fixed location which is obvious from this plot.
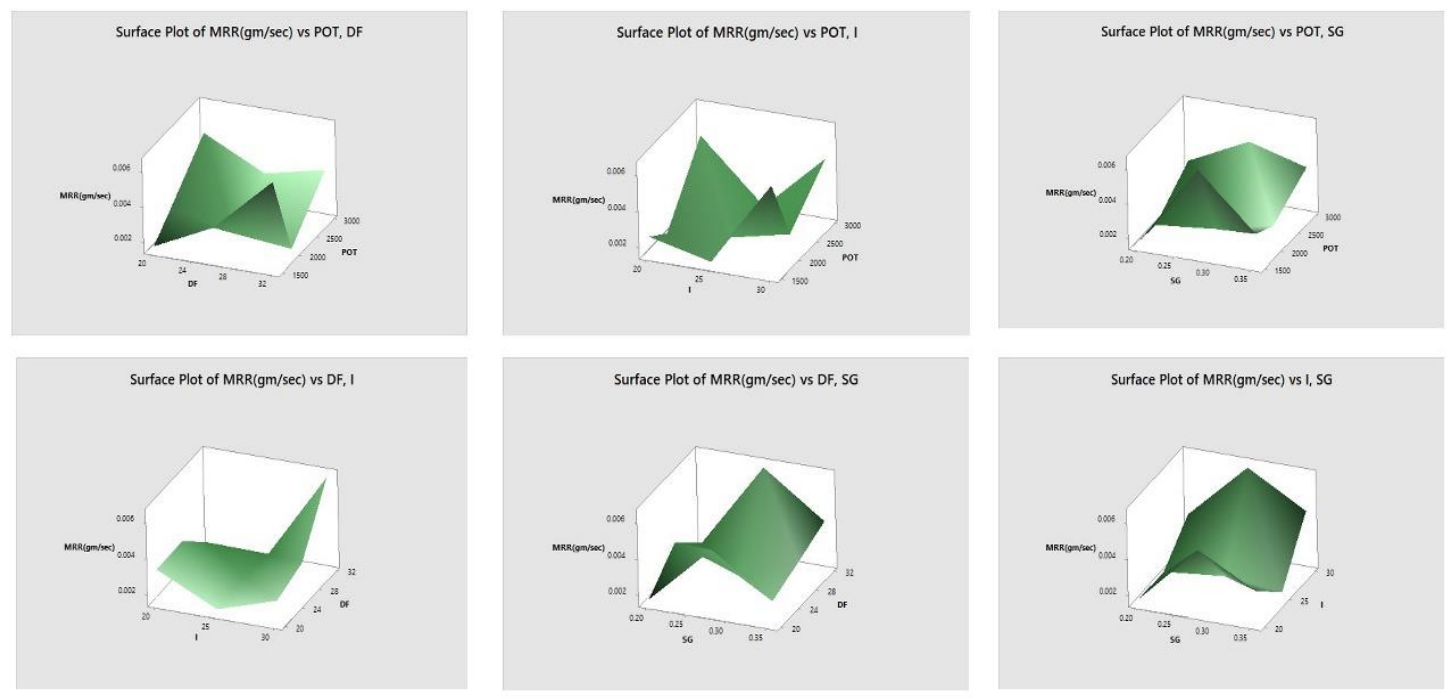

Fig. 9. Surface plot for the results of material removal rate 
International Journal of Mathematical, Engineering and Management Sciences

Vol. 3, No. 3, 301-314, 2018

https://dx.doi.org/10.33889/IJMEMS.2018.3.3-022

\subsection{Analysis of the Test Result for Over Cut}

The response surface (RSM) graph of OC regarding POT, DF, SG and I are shown in Fig. 10. In these plots, the variation of $\mathrm{OC}$ is shown in the $\mathrm{z}$-axis and two control parameters are taken in $\mathrm{x}$ axis and y-axis respectively, while other two parameters are kept constant. The graph manifest that the highest levels of the control parameters produce a maximum response. Subsequently the response is supported by the variables therefore they cannot have any fixed location which is obvious from this plot. (Ojha et al., 2012).
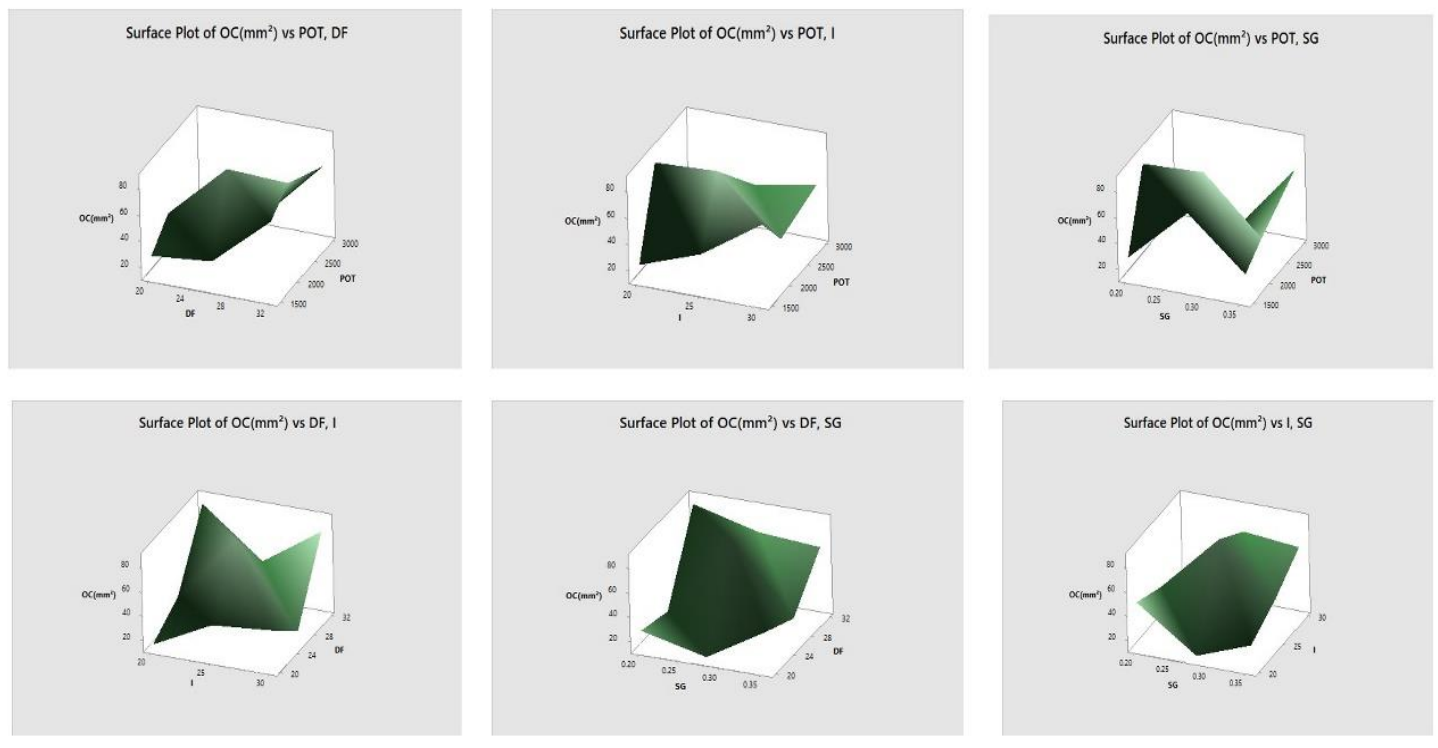

Fig. 10. Surface plot for the results of over cut

\section{Simultaneous Optimization of Responses}

\subsection{Overlaid Contour Plots}

High material removal rate and low over cut are the two main contradictory features for optimizing the complex process like EDM process. Both responses are contradictory, so, achieving them instantaneously by a single set of the optimum interchangeable mixture is rather tough. In this research work the multi-response optimization is applied in order to achieve these two conflicting goals concurrently. The levels of operating parameters are reviewed and satisfied those two constrained objectives by overlay control plots.

\subsection{Analysis of the Test Result Using Control Plot}

The overlaid control plots of responses with respect to control parameters are shown in Fig. 11. In these plots two control parameters are taken in $\mathrm{x}$-axis and $\mathrm{y}$-axis, while other two parameters are kept constant. The continuous line in the plot represents the lower boundary while the dotted line represents the upper boundary of the responses. The white area is the feasible region, where all the responses are optimizing simultaneously. 
International Journal of Mathematical, Engineering and Management Sciences

Vol. 3, No. 3, 301-314, 2018

https://dx.doi.org/10.33889/IJMEMS.2018.3.3-022
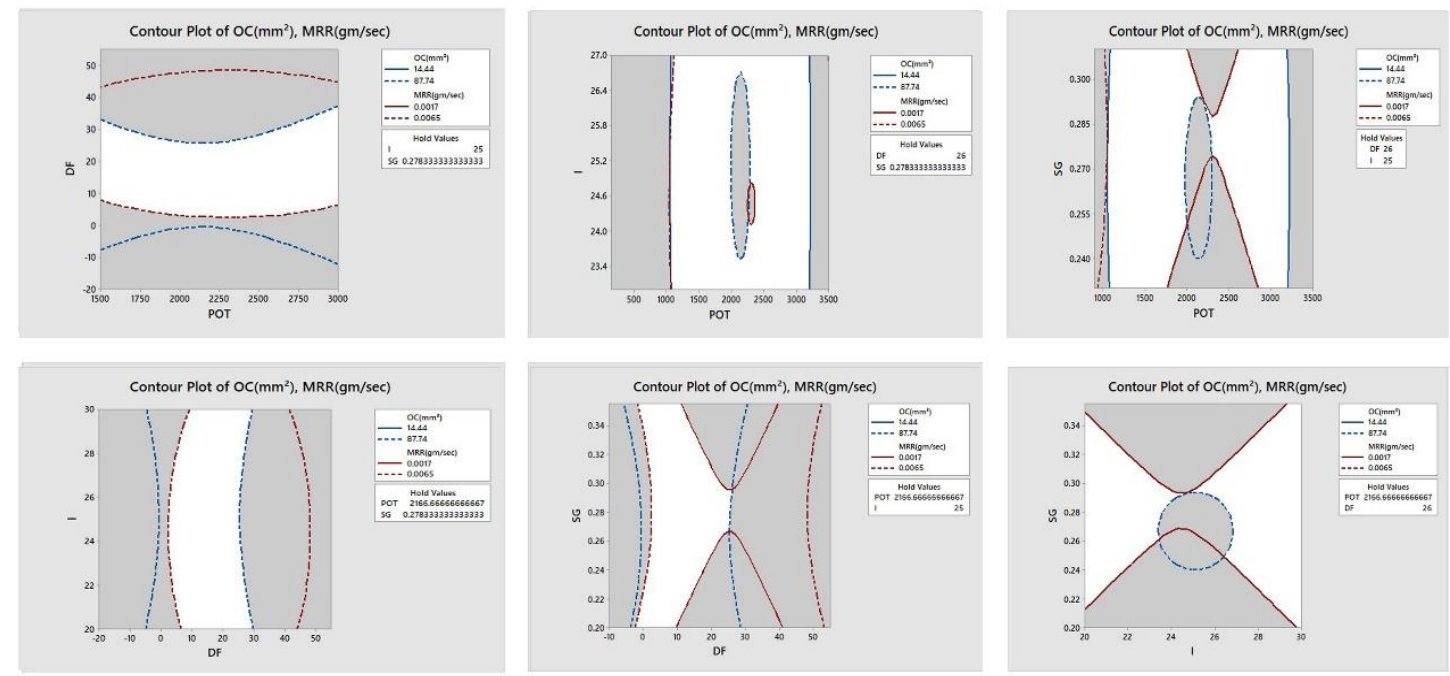

Fig. 11. Control plots of responses

\section{Desirability Functions}

The response optimizer can recognize the pattern and can help to optimize a single response as well as a set of responses. For a set of responses, the criteria for all the responses are taken care at the same time. (Cho and Park, 2006; Jeong and Kim, 2009). The basic attempt is to initially convert each response into a separate desirability function that differs with in a range (0 to 1) (Salmasnia et al., 2013). Here for over cut the target is set as minimum and for MRR the target is set as maximum. The significant parameter(s) choose how the desirability function can combine in a single composite desirability. Then finally the overall desirability function as well as composite desirability is calculated as per the individual mean of the functions.

\subsection{Analysis of the Test Result Using Desirability Functions}

The response optimization is presented in Table 4 below.

Table 4. Desirability function result

\begin{tabular}{|l|l|c|c|l|}
\hline Responses & Goal & $\begin{array}{l}\text { Lower } \\
\text { boundary }\end{array}$ & $\begin{array}{l}\text { Upper } \\
\text { boundary }\end{array}$ & Weight \\
\hline MRR & Maximum & 0.0017 & 0.0065 & 1 \\
\hline OC & Minimum & 14.44 & 87.74 & 1 \\
\hline Predicted Responses & Global Solution \\
MRR $=0.0058 \mathrm{gm} / \mathrm{sec}$, desirability $=0.85933(85.933 \%)$ & $\mathrm{POT}=3000 \mu \mathrm{S}$ \\
$\mathrm{OC}=14.9109 \mathrm{~mm}^{2}$, desirability $=0.99355(99.355 \%)$ & $\mathrm{DF}=20$ \\
\multicolumn{3}{|l}{} & $\mathrm{I}=30 \mathrm{amp}$ \\
Composite Desirability $=0.9257(92.57 \%)$ & $\mathrm{SG}=0.2894 \mathrm{~mm}$ \\
\hline
\end{tabular}


International Journal of Mathematical, Engineering and Management Sciences

Vol. 3, No. 3, 301-314, 2018

https://dx.doi.org/10.33889/IJMEMS.2018.3.3-022

Fig. 12 illustrate the optimized graph of the response parameters MRR and OC with the process control variables. The desirable response of MRR becomes $85.933 \%$ with the predicted response of $0.0058 \mathrm{gm} / \mathrm{sec}$, similarly the desirability of OC becomes $99.355 \%$ having the predicted response $14.911 \mathrm{~mm}^{2}$. Hence composite desirability is $92.40 \%$ having the paramedic combination of $\mathrm{POT}=3000 \mu \mathrm{S}, \mathrm{DF}=20, \mathrm{I}=30 \mathrm{amp}$ and $\mathrm{SG}=0.2894 \mathrm{~mm}$ for a multi objective optimal solution for higher MRR and lower OC.

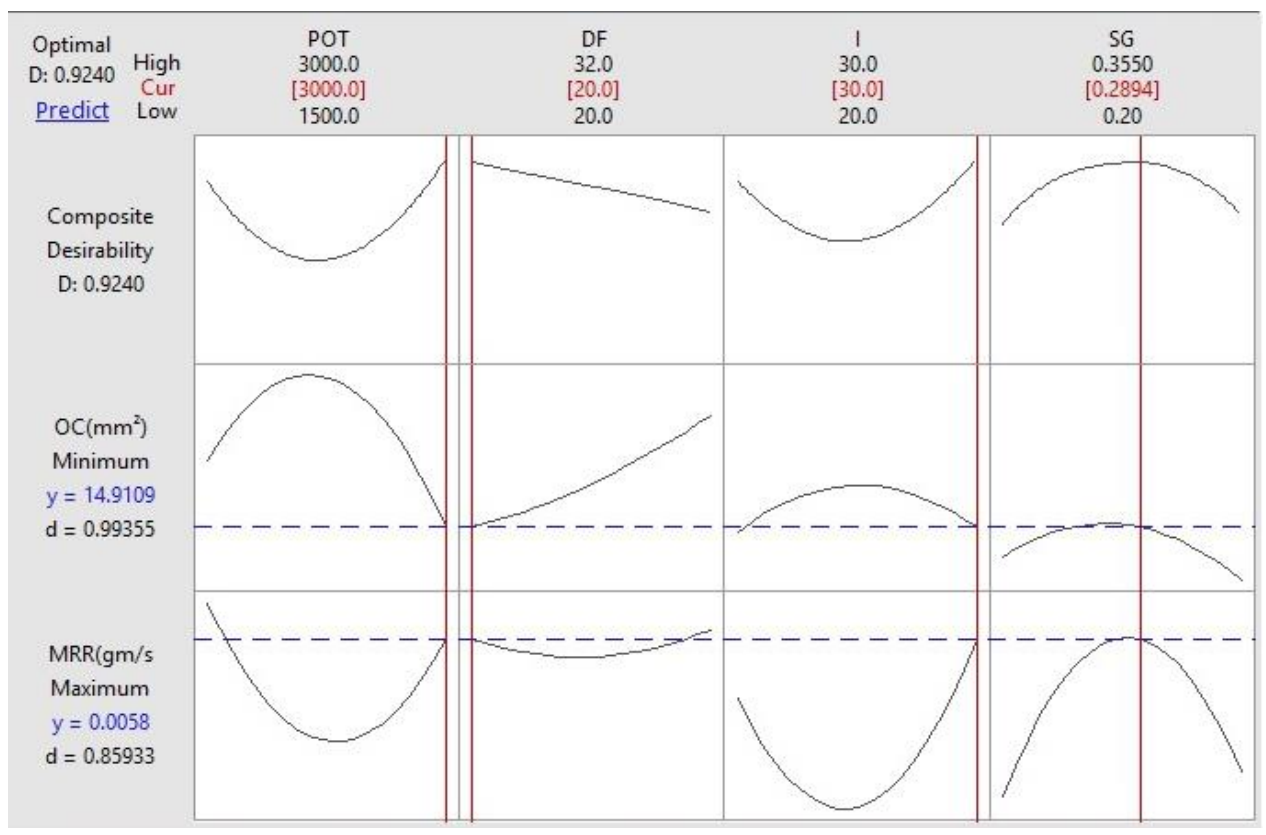

Fig. 12. Plot showing responses parameters versus process variables

\section{Conclusion}

The present paper attempts to validate and optimize the machining variables while machining of Mild Steel by EDM. The regression models are evaluated to fully clarify input-output corelationship with an accurate probability. It is found that the MRR is mostly influenced by POT whereas OC is affected by I. Histogram for MRR shows a truncated distribution from right to left and for OC histogram also shows a skewed distribution from left to right. The points in the normal probability plot form a straight line for all the responses since the residuals are normally distributed. For each residual versus response, plots have a recognizable pattern, so this model has room for improvement. The single response optimization is then found out using response surface methodology which finds the optimal solution. Then the multi-objective optimization is carried out by employing overlaid control plot. The overlaid control plot can recognize a desirable region where the responses can have the best value. The reasonable region is obtained for Material Removal Rate (MRR) which is between $0.0065 \mathrm{gm} / \mathrm{sec}$ to $0.0017 \mathrm{gm} / \mathrm{sec}$ and for Over Cut (OC) between $87.44 \mathrm{~mm} 2$ to $14.44 \mathrm{~mm}^{2}$. The clarifications obtained from the regression analysis is highlighted with the desirability functions. In order to attain maximum MRR, and minimum OC 
International Journal of Mathematical, Engineering and Management Sciences

Vol. 3, No. 3, 301-314, 2018

https://dx.doi.org/10.33889/IJMEMS.2018.3.3-022

the possible parametric combination of the control parameters is $\mathrm{POT}=3000 \mu \mathrm{S}, \mathrm{DF}=20, \mathrm{I}=30 \mathrm{amp}$ and $\mathrm{SG}=0.2894 \mathrm{~mm}$.

Hence, the analytical findings for evaluating the optimum parametric combination of Electric Discharge Machining of Mild Steel can perform an important role and an efficient guideline for manufacturing of complex products of similar material.

\section{References}

Aliakbari, E., \& Baseri, H. (2012). Optimization of machining parameters in rotary EDM process by using the Taguchi method. The International Journal of Advanced Manufacturing Technology, 62(9-12), 1041-1053.

Cho, Y. H., \& Park, S. H. (2006). Optimization in multi response model with modification desirability function. Asian Journal on Quality, 7(3), 46-57.

Jeong, I. J., \& Kim, K. J. (2009). An interactive desirability function method to multi-response optimization. European Journal of Operational Research, 195(2), 412-426.

Kiyak, M., \& Cakir, O., (2007). Examination of machining parameters on surface roughness in EDM tool steel. Journal of Materials Processing Technology, 191(1-3), 141-144.

Krishna, V. M., \& Xavior, A. M. (2015). Experiment and statistical analysis of end milling parameters for $\mathrm{Al} / \mathrm{SiC}$ using response surface methodology. International Journal of Engineering and Technology, 7(6), 2274-2285.

Lin, Y. C., Tsao, C. C., Hsu, C. Y. Hung, S. K., \& Wen, D. C. (2012). Evaluation of the characteristics of the micro-electrical discharge machining process using response surface methodology based on the central composite design. The International Journal of Advanced Manufacturing Technology, 62(9-12), 10131023.

Meena, V. K., \& Nagahanumaiah (2006). Optimization of EDM machining parameters using DMLS electrode. Rapid Prototyping Journal, 12(4), 222-228.

Montogomery, D. C., (2003). Design and analysis of experiment. John Willey \& Sons. Inc New York.

Nadpara, V. J., \& Choudhary, A. (2014). Optimization of EDM process parameters using Taguchi method with graphite electrode. International Journal of Engineering Trends and Technology, 7(2), 48-51.

Nipanikar, S. R. (2012). Parameter optimization of electro discharge machining of AISI d3 steel material by using Taguchi method. Journal of Engineering Research and Studies, 3(3), 7-10.

Ojha, K., Garg, R. K., \& Sing, K. K. (2012). An investigation into the effect of nickel micro powder suspends dielectric and varying triangular shape electrode measures of EN-19 steel. International Journal of Mechatronics and Manufacturing System, 5(1), 66-92.

Pandey, A. K., Tiwari, K., \& Dubey, A. K. (2014) Optimization of the process parameters in micro-electric discharge machining using response surface methodology and genetic algorithm. International Journal of Scientific and Research Publications, 4(9), 1-5.

Salmasnia, A., Bashiri, M., \& Salehi, M. (2013). A robust interactive approach to optimize correlated multiple responses. The International Journal of Advanced Manufacturing Technology, 67(5-8), 19231935.

Sharma, P., Singh, S., \& Mishra, D. R. (2014). Electrical discharge machining of AISI 329 stainless steel using copper and brass rotary tubular electrode. Procedia Materials Science, 5, 1771-1780. 
International Journal of Mathematical, Engineering and Management Sciences

Vol. 3, No. 3, 301-314, 2018

https://dx.doi.org/10.33889/IJMEMS.2018.3.3-022

Varun, A., Venkaiah, N., \& Kotiveerachari, B. (2012). Multi-objective optimization of powder mixed EDM. In 4th International \& 25th All India Manufacturing Technology, Design and Research Conference (AIMTDR), 453 - 459.

Vinoth, K. S., \& Pradeep, K. M. (2014). Optimization of cryogenic cooled EDM process parameters using grey relational analysis. Journal of Mechanical Science and Technology, 28(9), 3777-3784.

Vishwakarma, M., Parshar, V., \& Khare, V. K. (2012). Regression Analysis and optimization of material removal rate on electric discharge machine for EN -19 alloy steel. International Journal of Scientific and Research Publications, 2(11), 1-7. 